\title{
LETTER
}

\section{Dextran and hydroxyethyl starch do not interfere with fibrinogen measurement if Clauss method with mechanical clot detection is used}

\author{
Jose Mateo ${ }^{* 1}$, Pilar Paniagua ${ }^{2}$, Tobias Koller², Victoria Moral and Jordi Fontcuberta' \\ See related research by Rossaint et al., http://ccforum.com/content/14/2/R52
}

In an updated European guideline for the management of bleeding following major trauma, published in a recent issue of Critical Care, Rossaint and colleagues [1] recommended that thrombelastometry instead of other laboratory methods be used to measure fibrinogen. The authors stated that the Clauss method [2] overestimates fibrinogen concentration when colloids are given. This claim is supported by studies of patients receiving colloids in which fibrinogen was measured by an automated Clauss assay performed on an ACL-300R coagulometer (Instrumentation Laboratory, Bedford, MA, USA), which detects clot formation photo-optically [3]. Automated coagulometers use different technologies to detect fibrin clot endpoints. Some coagulometers employ mechanical principles involving the movement of a metal hook or the clot impedance of a ball bearing in a magnetic field; others use photo-optical devices to measure changes in light transmission [2].

Recently, Adam and colleagues [4] analyzed plasma diluted with different proportions of saline or hydroxyethyl starch (HES). Fibrinogen concentration was overestimated if the clotting time was measured photooptically in samples diluted with HES. But fibrinogen measurements in analyzers that used mechanical clot detection endpoints were accurate. Fenger-Eriksen and colleagues [5] assessed the accuracy of fibrinogen measurements in different analyzers and different methods in plasma diluted in different proportions with saline, HES, and albumin. The authors found that the photo-optical measurement overestimated fibrinogen concentration but that mechanical detection did not. Thromboelastometry seems to be a rapid and accurate

\footnotetext{
*Correspondence: jmateo@santpau.cat

'Thrombosis and Hemostasis Unit, Hospital de la Santa Creu i Sant Pau, C/ St Antoni M Claret 167, 08025-Barcelona, Spain
}

estimation of the level and function of fibrinogen but is not available in most centers. However, most laboratories can easily measure fibrinogen by the Clauss method using mechanical detection. We recommend that the European guidelines specifying the use of thromboelastometry over the Clauss method be revised and qualified accordingly.

Abbreviation
HES, hydroxyethyl starch.

Competing interests

The authors declare that they have no competing interests.

\section{Author details}

'Thrombosis and Hemostasis Unit, Hospital de la Santa Creu i Sant Pau, C/ St Antoni M Claret 167, 08025-Barcelona, Spain. ${ }^{2}$ Anesthesiology Department, Hospital de la Santa Creu i Sant Pau, C/ St Antoni M Claret 167, 08025-Barcelona, Spain.

Published: 12 September 2011

\section{References}

1. Rossaint R, Bouillon B, Cerny V, Coats TJ, Duranteau J, Fernández-Mondéjar E, Hunt BJ, Komadina R, Nardi G, Neugebauer E, Ozier Y, Riddez L, Schultz A, Stahel PF, Vincent JL, Spahn DR; Task Force for Advanced Bleeding Care in Trauma: Management of bleeding following major trauma: an updated European guideline. Crit Care 2010, 14:R52.

2. Mackie IJ, Kitchen S, Machin SJ, Lowe GD: Guidelines on fibrinogen assays. BrJ Haematol 2003, 121:396-404.

3. Hiippala ST: Dextran and hydroxyethyl starch interfere with fibrinogen assays. Blood Coagul Fibrinolysis 1995, 6:743-746.

4. Adam S, Karger R, Kretschmer V: Photo-optical methods can lead to clinically relevant overestimation of fibrinogen concentration in plasma diluted with hydroxyethyl starch. Clin Appl Thromb Hemost 2010, 16:461-471.

5. Fenger-Eriksen C, Moore GW, Rangarajan S, Ingerslev J, Sørensen B: Fibrinogen estimates are influenced by methods of measurement and hemodilution with colloid plasma expanders. Transfusion 2010, 50:2571-2576. doi:10.1186/cc10304

Cite this article as: Mateo J, et al.: Dextran and hydroxyethyl starch do not interfere with fibrinogen measurement if Clauss method with mechanical clot detection is used. Critical Care 2011, 15:441. 